\title{
The Madden-Julian Oscillation in NCEP Coupled Model Simulation
}

\author{
Wanqiu Wang ${ }^{1}$ and Kyong-Hwan Seo ${ }^{2, *}$ \\ ${ }^{1}$ Climate Prediction Center, NCEP/NWS/NOAA, Camp Springs, Maryland, USA \\ ${ }^{2}$ Division of Earth Environmental System, Pusan National University, Busan, Korea
}

Received 25 March 2008, accepted 17 September 2008

\begin{abstract}
This study documents a detailed analysis on the Madden-Julian Oscillation (MJO) simulated by the National Centers for Environmental Prediction (NCEP) using the Global Forecast System (GFS) model version 2003 coupled with the Climate Forecast System model (CFS) consisting of the 2003 version of GFS and the Geophysical Fluid Dynamics Laboratory (GFDL) Modular Ocean Model V.3 (MOM3). The analyses are based upon a 21-year simulation of AMIP-type with GFS and CMIP-type with CFS. It is found that air-sea coupling in CFS is shown to improve the coherence between convection and large-scale circulation associated with the MJO. The too fast propagation of convection from the Indian Ocean to the maritime continents and the western Pacific in GFS is improved (slowed down) in CFS. Both GFS and CFS produce too strong intraseasonal convective heating and circulation anomalies in the central-eastern Pacific; further, the air-sea coupling in CFS enhances this unrealistic feature. The simulated mean slow phase speed of eastward propagating low-wavenumber components shown in the wavenumber-frequency spectra is due to the slow propagation in the central-eastern Pacific in both GFS and CFS. Errors in model climatology may have some effect upon the simulated MJO and two possible influences are: (i) CFS fails to simulate the westerlies over maritime continents and western Pacific areas, resulting in an unrealistic representation of surface latent heat flux associated with the MJO; and (ii) vertical easterly wind shear from the Indian Ocean to the western Pacific in CFS is much weaker than that in the observation and in GFS, which may adversely affect the eastward propagation of the simulated MJO.
\end{abstract}

Key words: Madden-Julian Oscillation, CFS model, GFS model, AMIP, CMIP

Citation: Wang, W. and K.-H. Seo, 2009: The Madden-Julian Oscillation in NCEP coupled model simulation. Terr. Atmos. Ocean. Sci., 20, 713-725, doi: 10.3319/TAO.2008.09.17.01(A)

\section{INTRODUCTION}

Since the discovery of the tropical Madden-Julian Oscillation (MJO) over three decades ago (Madden and Julian 1971, 1972), most of the studies on the MJO have considered it a result of internal atmospheric dynamics involving the interaction between the convection and largescale circulation. While some major characteristics of the MJO can indeed be simulated by atmospheric models with prescribed sea surface temperatures (e.g., Hayashi and Golder 1986; Wang and Schlesinger 1999), results from many studies also suggest the importance of the air-sea interaction in the MJO dynamics. Observational diagnoses have shown coherent variations in surface heat fluxes, SST, and convection associated with the MJO (e.g., Krishnamurti

\footnotetext{
* Corresponding author

E-mail:khseo@pusan.ac.kr
}

et al. 1988; Zhang 1996, 1997; Hendon and Glick 1997; Jones et al. 1998; Kemball-Cook and Wang 2001; KemballCook et al. 2002; Maloney and Kiehl 2002; Sperber 2003; Hendon 2005), suggesting that inclusion of the coupled air-sea interaction in a numerical model may be necessary for a reasonable representation of the MJO. However, improvements in the MJO simulation by numerical models due to the inclusion of the air-sea coupling are model-dependent (Flatau et al. 1997; Waliser et al. 1999; Hendon 2000; Inness et al. 2003; Sperber 2004; Liess et al. 2004; Woolnough et al. 2007). When coupled together, models are capable of simulating observed relationships among convection, heat fluxes, and SSTs, the MJO in the models are indeed improved compared with atmosphere-only models, and if the models failed to capture the observed convection/heat-flux relationship due to a certain defi- 
ciency of the model (for example, erroneous mean surface wind), the simulated MJO was not improved by the inclusion of the air-sea interaction (Flatau et al. 1997; Waliser et al. 1999; Hendon 2000; Inness and Slingo 2003; Inness et al. 2003).

A new global coupled atmosphere-ocean Climate Forecast System model (CFS) has recently been developed at the National Centers for Environmental Prediction (NCEP) (Saha et al. 2006; Wang et al. 2005). It consists of the NCEP atmospheric Global Forecast System model (GFS) and the Geophysical Fluid Dynamics Laboratory (GFDL) Modular Ocean Model V.3 (MOM3). In this study, we diagnose the characteristics of the MJO simulated by the uncoupled atmospheric GFS and coupled atmosphere-ocean CFS to compare the simulations with observation and document the role of the air-sea interaction. The diagnoses will be based on free simulations by GFS and CFS, and will focus on the periodicity, propagation, and coherence among the associated fields of the MJO. For an analysis on the boreal summer intraseasonal oscillation, refer to Seo et al. (2007).

\section{THE MODELS AND OBSERVATIONAL DATA}

\subsection{The Models}

The atmospheric component of the coupled CFS is the operational version of the NCEP Global Forecast System model (GFS) as of February 2003. It adopts a spectral truncation of 62 waves (T62) in the horizontal and a finite differencing in the vertical with 64 sigma layers. The oceanic component is the Geophysical Fluid Dynamics Laboratory (GFDL) Modular Ocean Model V.3 (MOM3) (Pacanowski and Griffies 1998). The adopted domain for MOM3 in CFS is quasi-global extending from $74^{\circ} \mathrm{S}$ to $64^{\circ} \mathrm{N}$. The zonal resolution is $1^{\circ}$. The meridional resolution is $1 / 3^{\circ}$ between $10^{\circ} \mathrm{S}$ and $10^{\circ} \mathrm{N}$, gradually increasing through the tropics until becoming fixed at $1^{\circ}$ poleward of $30^{\circ} \mathrm{S}$ and $30^{\circ} \mathrm{N}$. There are 40 layers in the vertical with 27 layers in the upper $400 \mathrm{~m}$. The atmospheric and oceanic components are coupled without any flux adjustment. Sea ice extent is prescribed from the observed climatology. More details of the CFS model can be found in Saha et al. (2006) and Wang et al. (2005).

\subsection{The Simulations and Observations}

Diagnoses in this report are based on an AMIP-type simulation with GFS and a CMIP-type simulation with CFS. The AMIP-type simulation with GFS was forced with observed sea surface temperatures (SSTs) from 1982 - 2002. The prescribed SSTs were taken from the weekly analysis of Reynolds et al. (2002) but low-pass filtered with a cutoff period of 150 days so that SST variability shorter than this cutoff period is largely removed. This treatment of SSTs is to ensure that the intraseasonal variability in the GFS simulation is due to the internal atmospheric dynamics. While many AMIP simulations were conducted with monthly mean SSTs, Wang et al. (2004) showed that an appreciable fraction of intraseasonal variability may be forced by the use of monthly-mean SSTs, which complicates the diagnoses of the intraseasonal variability resulting from the interaction between convection and large-scale circulation in the atmosphere.

Several CMIP multi-decade simulations have been performed with CFS, which have been diagnosed to investigate the model's capability in simulating interannual variability (Wang et al. 2005). In this report, the first 21-year segment from one of the CFS simulations will be used. This simulation was initialized from observed analyses of 1 January 2002. The initial condition for the atmosphere was taken from the NCEP/DOE Reanalysis-2 (R2) (Kanamitsu et al. 2002) and the initial condition for the ocean was from an NCEP global ocean data assimilation system (GODAS) (e.g., Seo and Xue 2005).

Model simulations will be compared with observations. The observational data to be used include: daily SSTs interpolated from the weekly analysis of Reynolds et al. (2002), NCEP/DOE R2, the Climate Prediction Center merged analysis of precipitation (CMAP) (Xie and Arkin 1997), and the daily outgoing longwave radiation (OLR) data from the National Oceanic and Atmospheric Administration (NOAA) polar-orbiting series of satellites (Liebmann and Smith 1996).

All fields used to diagnose intraseasonal variability are either direct daily average, or daily values interpolated from weekly (e.g., the observed SSTs) or pentad (e.g., the CMAP precipitation) analyses. Calculations for intraseasonal variability are based on 10 - 100-day band-pass filtered time series. In the following, we will first describe some aspects of the climatology that may have impacts on intraseasonal variability. We will then document the intraseasonal variability and compare the MJO characteristics between the simulations and observations.

\section{CLIMATOLOGY}

\subsection{SSTs}

Simulated annual-mean SST errors by CFS are shown in Fig. 1. As in most coupled models without flux corrections, warm and cold SST biases are present in the CFS simulation. A warm SST bias with a magnitude of $\sim 2.5 \mathrm{~K}$ is found over the south-eastern Pacific and Atlantic stratus deck region, while sizeable cold SST biases are observed over the tropical and subtropical western Pacific.

\subsection{Precipitation Rate}

Figure 2 compares annual-mean precipitation rate between simulations and observation. The deficiencies in the GFS simulation include: too little precipitation in the equatorial western Pacific and eastern Indian Ocean, too strong 
ITCZ, and too much precipitation in most of the subtropical regions. CFS simulates a weaker ITCZ compared with GFS. However, the deficiencies of too little precipitation in the equatorial western Pacific and eastern Indian Ocean and too much precipitation in most of the subtropical regions remain in the CFS simulation. In particular, CFS produces a double-ITCZ structure, which is possibly associated with the warm SST bias in the south-eastern Pacific stratus deck region (Fig. 1).

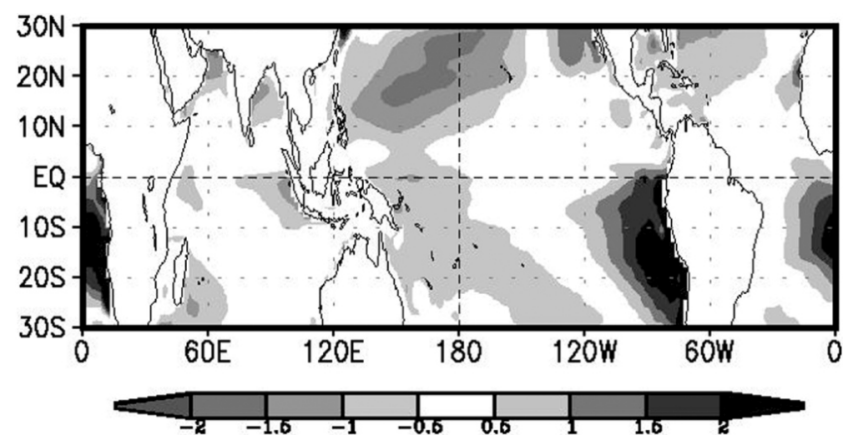

Fig. 1. Simulated annual-mean sea surface temperature errors $(K)$ by CFS. The errors are defined as the mean differences between CFS simulation and the analysis of Reynolds et al. (2002). Values are shaded at an interval of $0.5 \mathrm{~K}$.

(a) CMAP
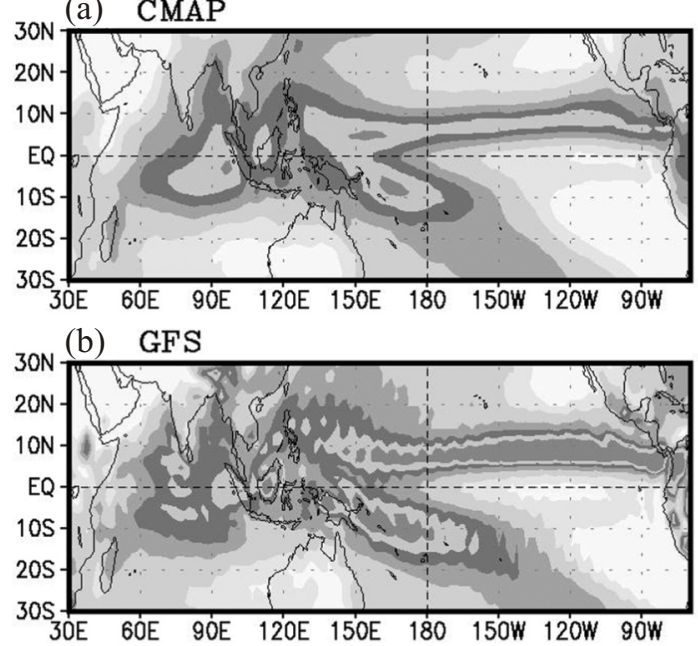

(c) CFS

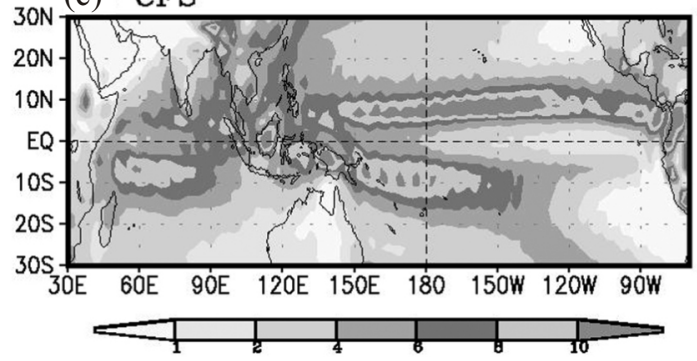

\subsection{0-hPa Zonal Wind}

Realistic zonal surface winds have been shown to be an important factor for reasonable representation of surface latent heat flux (Hendon 2000; Inness and Slingo 2003). Simulated and observational $1000-\mathrm{hPa}$ zonal winds are presented in Fig. 3. The major deficiency in the CFS simulation is too weak westerlies in the Indian Ocean and over the maritime continents (Fig. 2c). The simulated 1000-hPa zonal winds by GFS (Fig. 2b) are also weaker than that observed but with smaller errors compared with that by the CFS. The weaker westerlies in CFS over the Indian Ocean and the maritime continents are consistent with the negative SST errors in CFS (Fig. 1). Since the surface winds and SST interact with each other, the weaker westerlies in CFS suggest that the weaker Walker circulation would induce cooler SSTs, which in turn would further weaken the surface westerlies. The errors in surface tropical zonal winds in CFS are more significant in northern cold seasons (November to April) during which the equatorial zonal winds over the maritime continents and in the western Pacific in the CFS simulation near the equator are very weak while observations and GFS exhibit relatively strong westerlies (not shown).
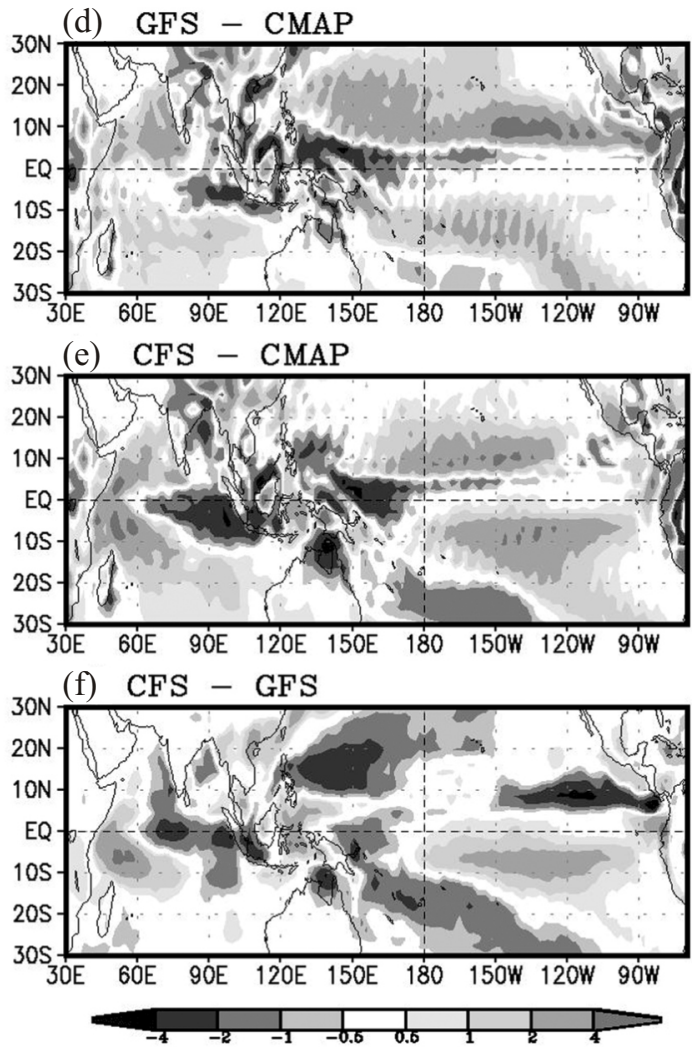

Fig. 2. Annual-mean climatology of precipitation ( $\mathrm{mm} \mathrm{day}^{-1}$ ) from (a) CMAP, (b) GFS simulation, (c) CFS simulation, (d) GFS - CMAP, (e) CFS CMAP, and (f) CFS - GFS. Values are shaded at $1,2,4,6,8$, and $10 \mathrm{~mm}$ day in (a) to (c), and at $-4,-3,-2,-1,-0.5,0.5,1,2,3$, and 4 mm day ${ }^{-1}$ in (d) to (f). 


\subsection{Atmospheric Equatorial Zonal Winds}

Another factor that affects the evolution of the MJO is the vertical wind shear. Fig. 4 compares annual mean climatology of zonal wind averaged from $10^{\circ} \mathrm{S}$ to $10^{\circ} \mathrm{N}$. The observed strong easterly shear in the Indian Ocean and western Pacific $\left(120-170^{\circ} \mathrm{E}\right)$ is not well simulated in CFS. This deficiency is largely corrected in the GFS simulation, indicating that, as in near-surface zonal wind (Fig. 3c), the errors in the vertical section of zonal wind in the Indian Ocean and western Pacific in the CFS simulation (Fig. 4c) are mainly due to the errors in the simulated SSTs (Fig. 1).

\section{INTRASEASONAL VARIABILITY}

Before presenting the variability associated with the specific MJO modes, we compare the overall amplitude of the simulated and observed intraseasonal variability of 850-hPa zonal wind and OLR. Root mean squared (RMS) amplitude of intraseasonal (10 - 100-day) components of

(a) R2

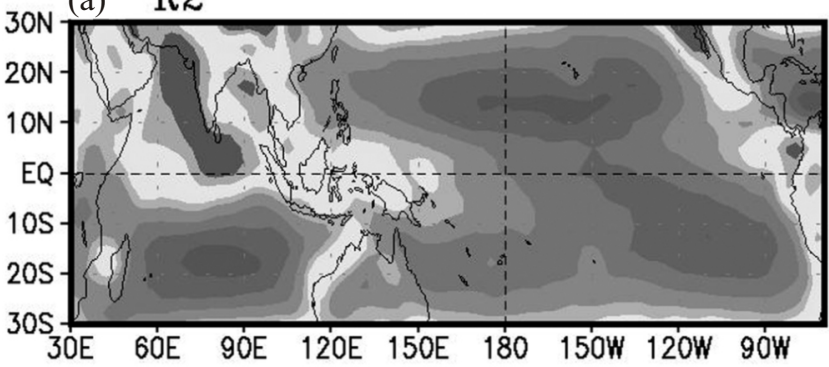

(b) GFS

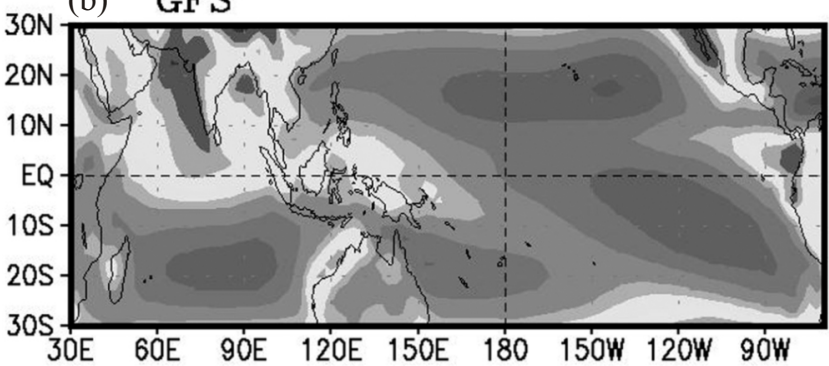

(c) $\mathrm{CFS}$

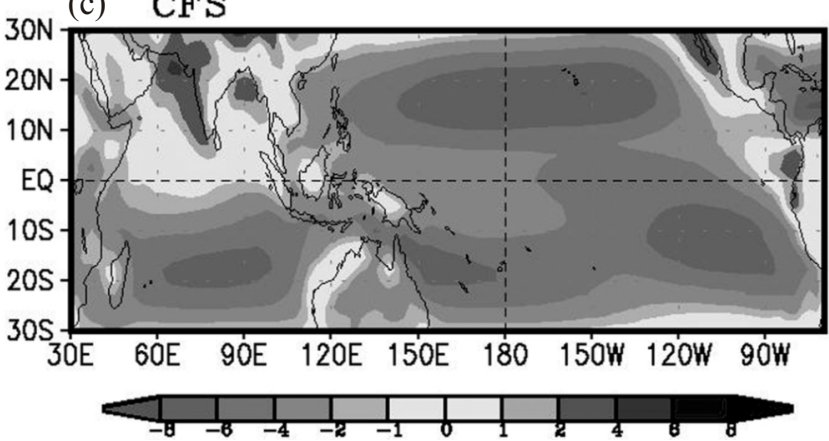

Fig. 3. Annual-mean $1000 \mathrm{hPa}$ zonal velocity ( $\mathrm{m} \mathrm{s}^{-1}$ ). (a) R2, (b) GFS, and (c) CFS. Contours are plotted at -8, -6, -4, -2, -1, 0, 1, 2, 4, 6, and 8 .
850-hPa zonal wind is shown in Fig. 5. The observational analysis shows a relatively large amplitude in the subtropics, and in the tropical western Pacific and eastern Indian Ocean (Fig. 5a). The amplitude over the maritime continents and southeastern Pacific are comparatively small. Both GFS and CFS (Figs. 5b, c) simulated the overall observed pattern but with lager amplitude over most of the tropics and subtropics, especially for the maritime continents and the central and eastern Pacific where the simulated amplitude is more than 20 percent larger than that observed (Figs. 5d, e).

Compared with GFS, CFS simulated weaker intraseasonal amplitude of 850-hPa zonal wind over the maritime continents, in the equatorial eastern Indian Ocean and western Pacific, and in most of the off-equator central Pacific areas. In the tropical western Indian Ocean and central eastern Pacific, the larger amplitude in the GFS simulation (Fig. 5d) compared with the observation is further enhanced in the CFS simulation (Figs. 5e, f).

A similar comparison is seen in the intraseasonal amplitude of OLR (Fig. 6), except that the amplitude ratio of the

\section{(a) $\mathrm{R2}$}

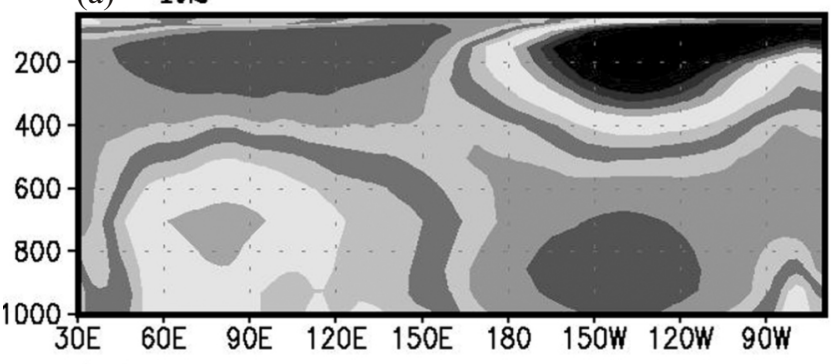

(b) GFS

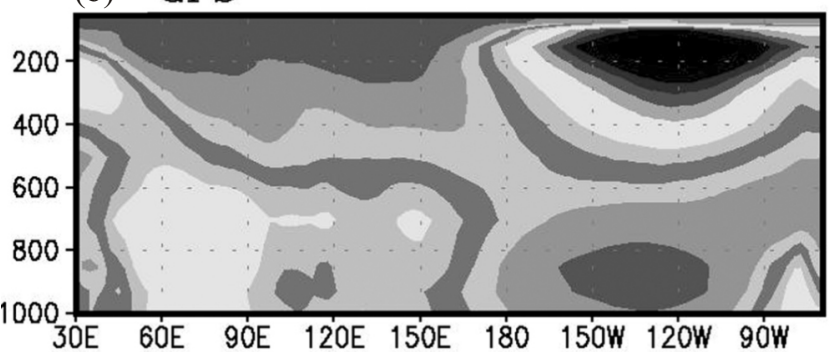

(c) CFS

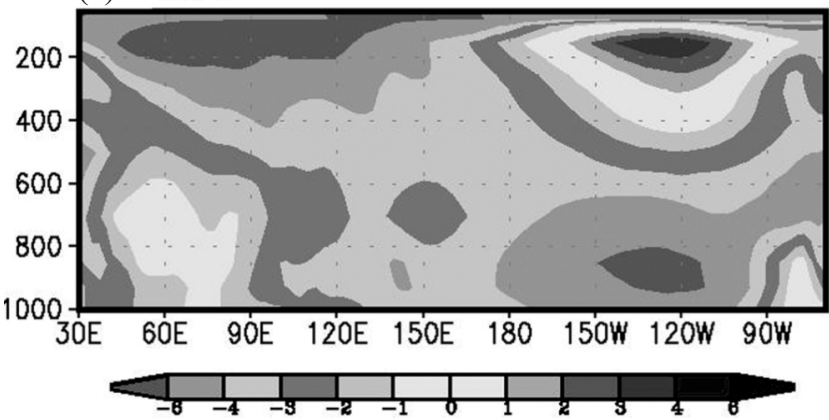

Fig. 4. Annual-mean climatology of $10^{\circ} \mathrm{S}$ to $10^{\circ} \mathrm{N}$ average zonal wind. (a) R2, (b) GFS, and (c) CFS. Values are shaded at -6, -4, -3, -2, -1, 0, 1, $2,3,4$, and $6 \mathrm{~m} \mathrm{~s}^{-1}$. 


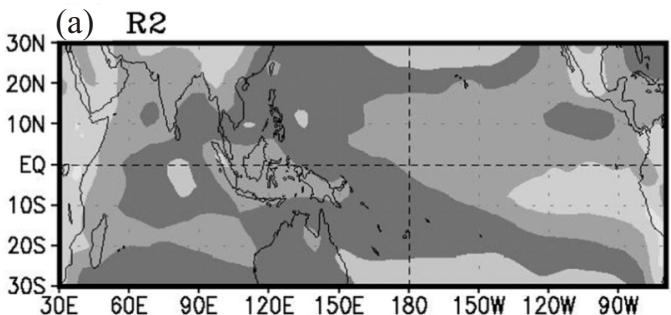

(b) GFS

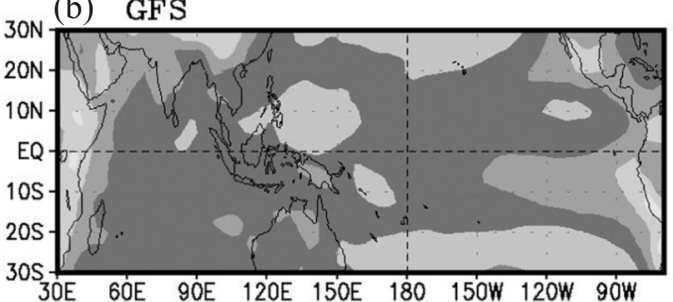

(c) CFS

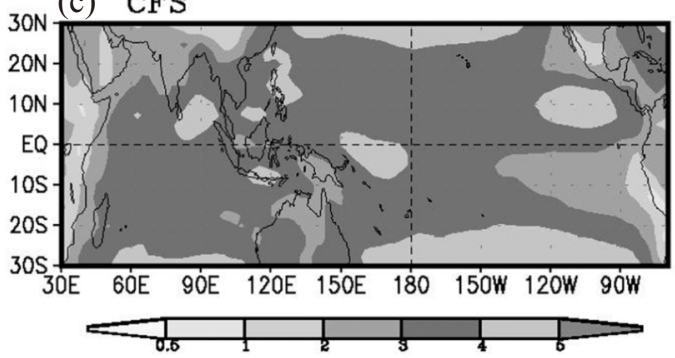

(d) GFS/R2

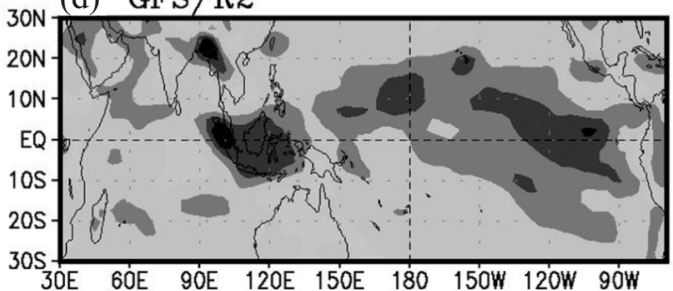

(e) $\mathrm{CFS} / \mathrm{R2}$
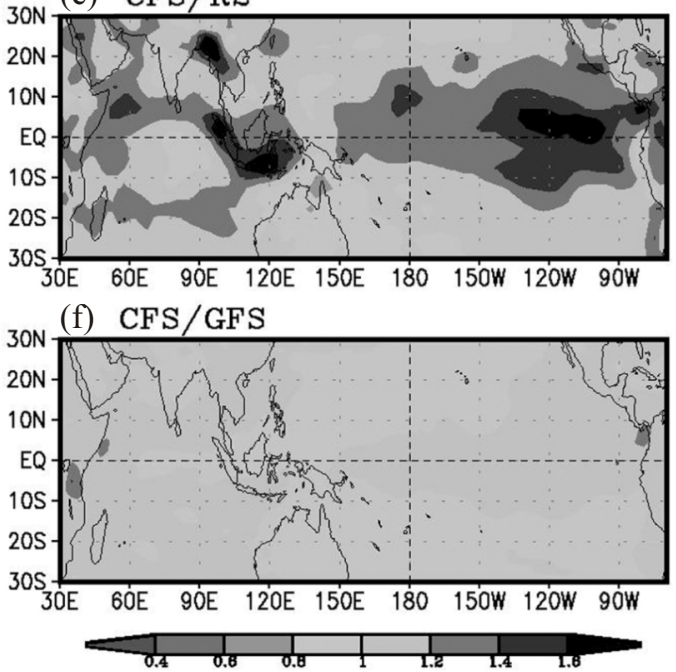

Fig. 5. Intraseasonal (10 - 100 day) root-mean-squared (RMS) amplitude of 850-hPa zonal wind. (a) R2, (b) GFS, (c) CFS, (d) ratio of GFS to R2, (e) ratio of CFS to R2, and (f) ratio of CFS to GFS. Unit is $\mathrm{m} \mathrm{s}^{-1}$ in (a), (b), and (c). Values are shaded at 0.5, 1, 2, 3, 4, and 5 in (a), (b), and (c), and at an interval of 0.2 in (d), (e), and (f).
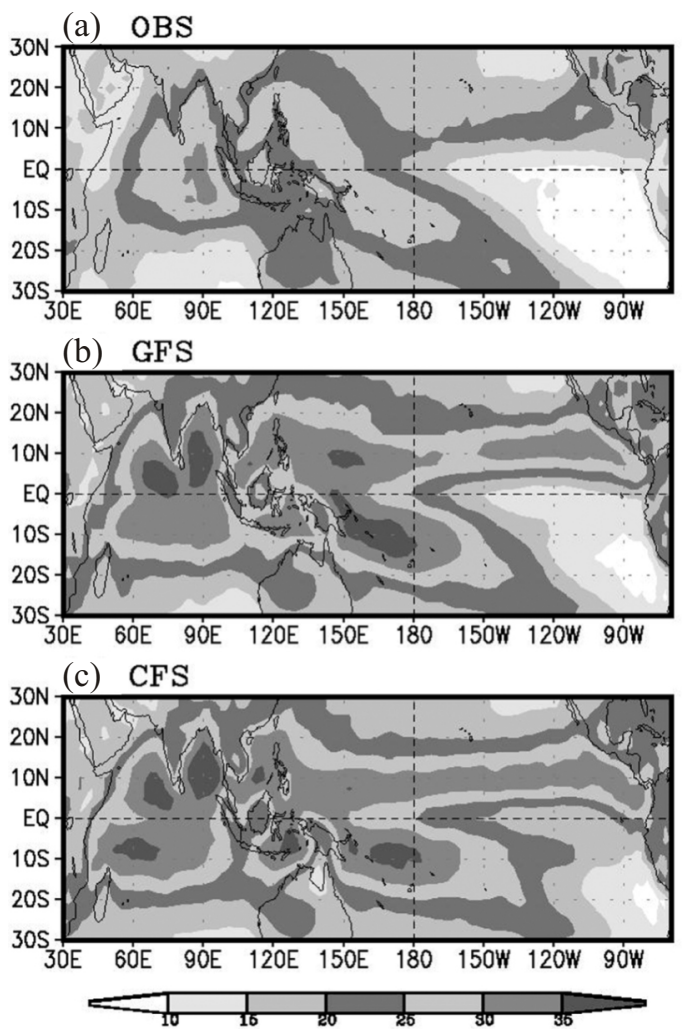

(d) GFS/OBS
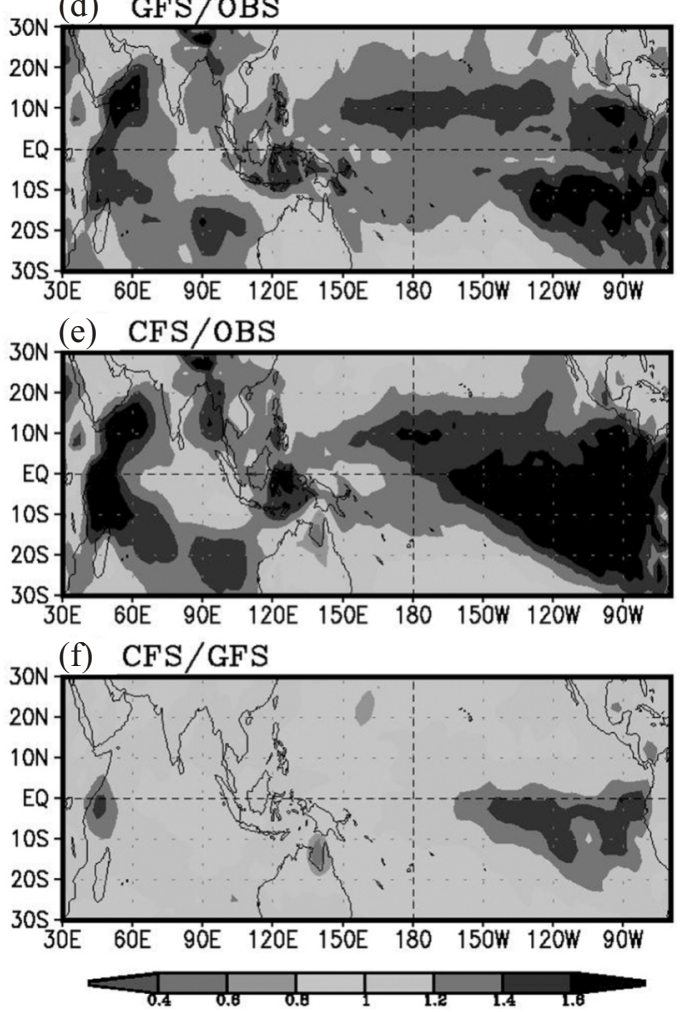

Fig. 6. As in Fig. 5, except for OLR. Unit is $\mathrm{W}^{-2}$ in (a), (b), and (c). 
simulated OLR to that observed (Figs. 6d, e) is even larger than that of $850-\mathrm{hPa}$ zonal wind (Figs. 5d, e). Comparison between the GFS to CFS amplitude ratio of OLR (Fig. 6f) and the CFS SST errors (Fig. 1) suggest that, to some extent, the weakening (enhancement) of the intraseasonal amplitude in CFS compared with that in GFS may be associated with local cold (warm) SST errors.

\section{THE SIMULATED MJO}

In this section we compare the MJO between simulations and observations to assess the model's performance and to examine the impact of the inclusion of the air-sea interaction on the simulated MJO. We will first diagnose the wavenumber-frequency power spectra of equatorial $850-\mathrm{hPa}$ zonal wind and 200-hPa velocity potential. We will then examine the leading Empirical Orthogonal Function (EOF) modes of the tropical intraseasonal variability of
OLR, 850-hPa zonal wind, and 200-hPa zonal wind, and the temporal evolution of the associated fields.

\subsection{Power Spectra of Tropical 850 hPa Zonal Velocity}

Figure 7 shows wavenumber-frequency power spectra of $10^{\circ} \mathrm{S}-10^{\circ} \mathrm{N}$ mean $850-\mathrm{hPa}$ zonal wind (u850). The spectra from R2 (Fig. 7a) are characterized by an eastwardpropagating wavenumber-1 peak around a period of 40 60 days. GFS simulated large eastward-propagating wavenumber-1 variance throughout the intraseasonal period range of 30 - 100 days with peak values near 60 - 80-day periods (Fig. 7b). Compared with the GFS simulation, the variance in CFS (Fig. 7c) is substantially enhanced. The peak values of the eastward-propagating wavenumber 1 are around 60 80 -day periods, similar to those in the GFS simulation. The amplitude of the spectra from CFS simulation is about twice as large as that from R2, indicating that the amplitude of
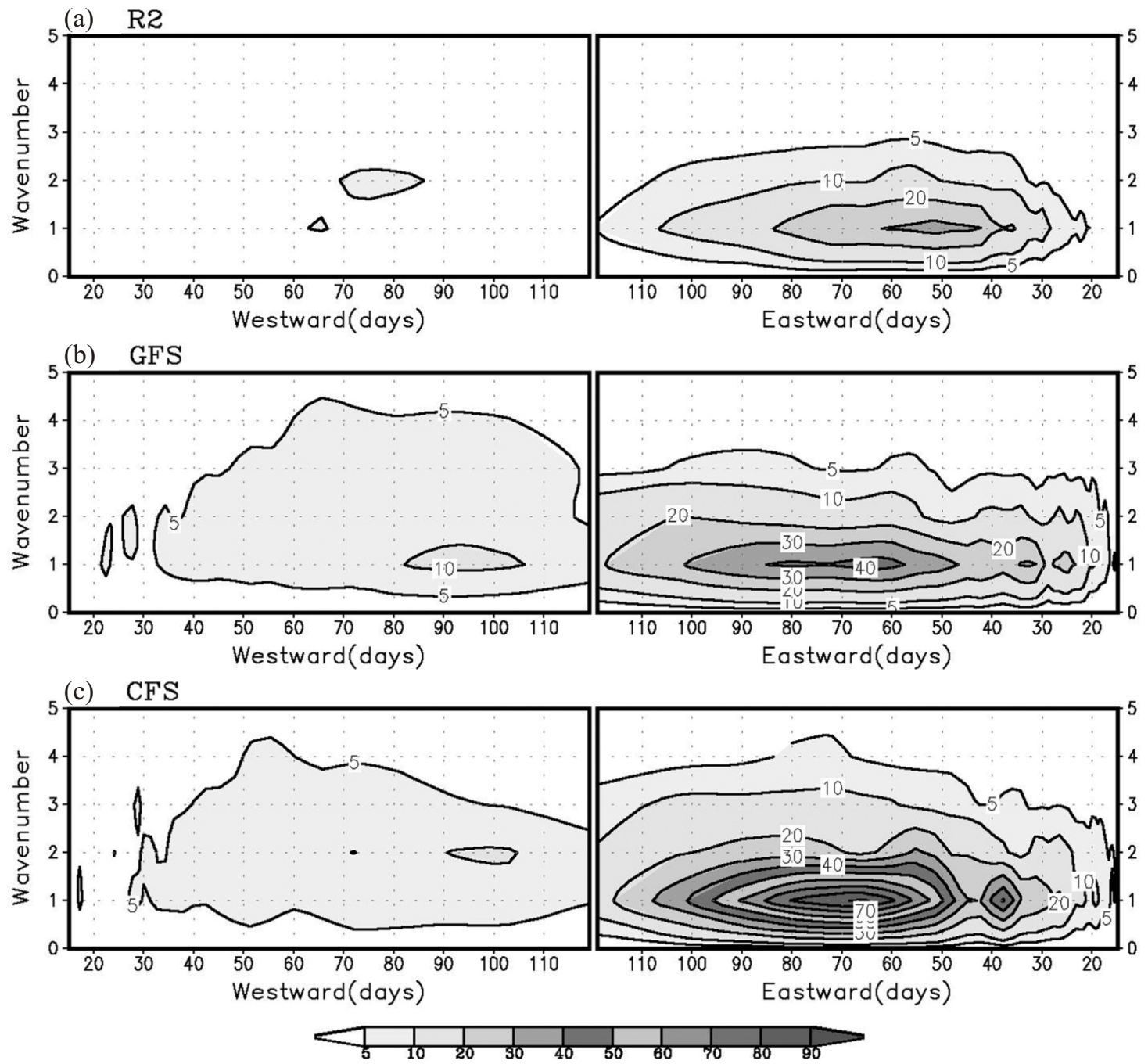

Fig. 7. Wavenumber-frequency spectra of $10^{\circ} \mathrm{S}-10^{\circ} \mathrm{N}$ mean $850 \mathrm{hPa}$ zonal wind $\left(\mathrm{m}^{2} \mathrm{~s}^{-2}\right.$ ) from (a) R2, (b) GFS, and (c) CFS. Contours are plotted at 5 , $10,20,30,40,50,60$, and 70 . 
intraseasonal anomalies in the CFS simulation is about 40 percent stronger than that in R2. Wavenumber-frequency power spectra of $10^{\circ} \mathrm{S}-10^{\circ} \mathrm{N}$ mean 200 -hPa velocity potential $(\chi 200)$ are also calculated (not shown). Overall features of $\chi 200$ wavenumber-frequency power spectra are similar to that of $\mathrm{u} 850$, except that the westward components are substantially weaker.

\subsection{EOF Modes of Combined Fields}

Following Wheeler and Hendon (2004), Empirical Orthogonal Functions (EOFs) of combined fields of $10^{\circ} \mathrm{S}-$ $10^{\circ} \mathrm{N}$ average of $850-\mathrm{hPa}$ zonal wind (u850), 200-hPa zonal wind (u200), and OLR are calculated to identify the MJO. The two leading EOF modes are shown in Fig. 8. EOF1 of the observations (Fig. 8a) is characterized by a strong convective heat source over the maritime continents and western Pacific ( 90 to $180^{\circ} \mathrm{E}$ ), and the consistent convergent flow in the lower troposphere and divergent flow in the upper troposphere. In EOF2 of the observations (Fig. 8d), strong convective heating source is seen in the Indian Ocean (60 to $\left.100^{\circ} \mathrm{E}\right)$. The convective heat source in the Indian Ocean corresponds to convergent flow in the lower troposphere and divergent flow in the upper troposphere.

The structures of the two leading EOFs in GFS (Figs. 8b, e) are similar to that in CFS (Figs. 8c, f). While the EOF1 convection in the observation is confined mostly to the eastern Indian Ocean, maritime continents and western Pacific with near zero heating in the central-eastern Pacific, large EOF1 convective heating in GFS and CFS is found in the central-eastern Pacific with strong associated circulation anomalies (Figs. 8b, c), especially for CFS. The western boundary of EOF 1 convective heating in the eastern Indian Ocean in GFS is located further east compared with that in CFS and in observations. Structures of EOF2 in GFS and CFS are similar to that in the observations with large convective heating located in the Indian Ocean. However, the circulation fields and convective heating in the simulations, especially for the GFS simulation, are less coherent than that in the observations.
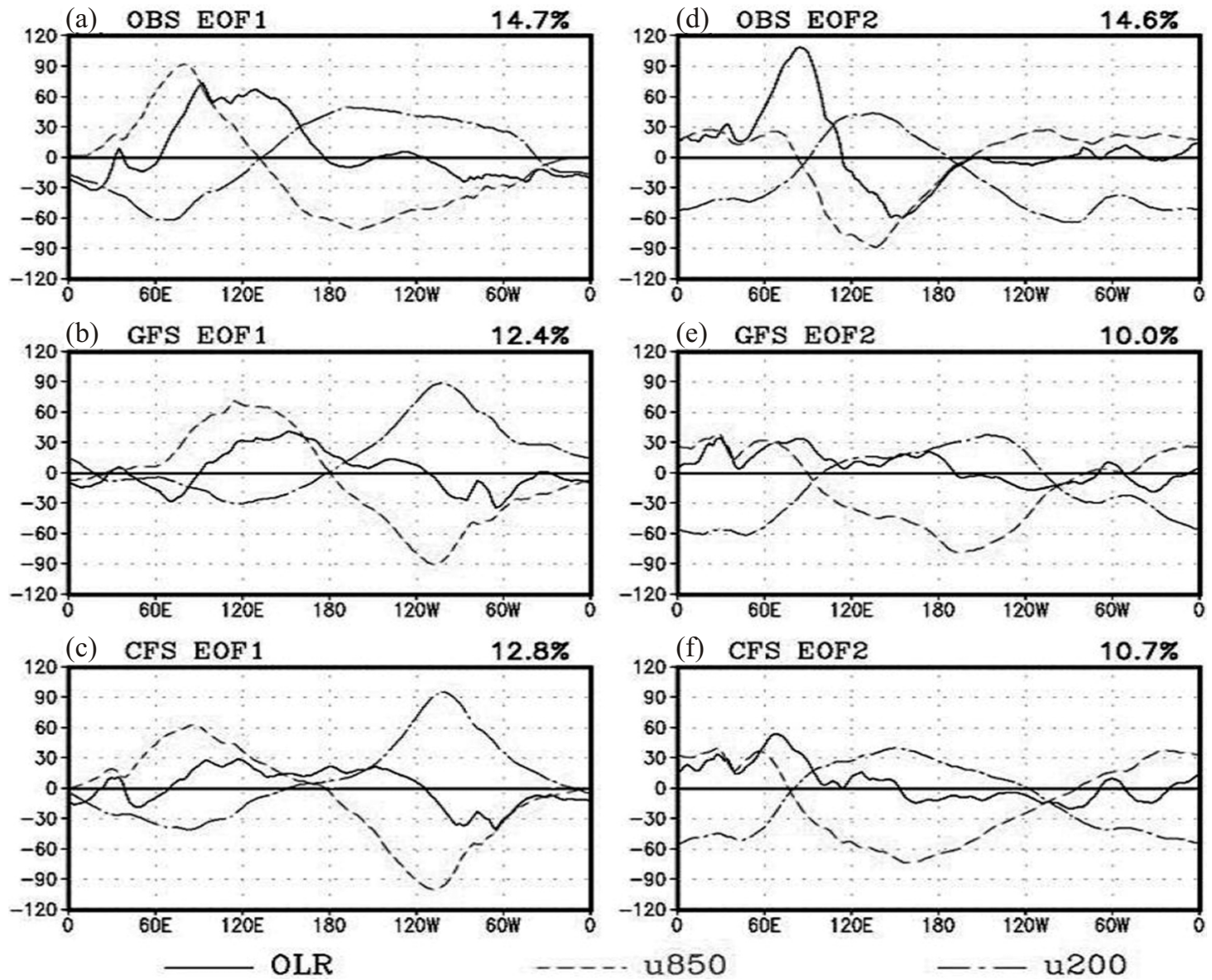

Fig. 8. Patterns of combined empirical orthogonal functions (EOFs) of 10 - 100 day filtered OLR, $850 \mathrm{hPa}$ zonal wind (u850), and 200 hPa zonal wind (u200). (a) EOF1 from observations, (b) EOF1 from GFS, (c) EOF1 from CFS, (d) EOF2 from observations, (e) EOF2 from GFS, and (f) EOF2 from CFS. Values of u850, u200, and-OLR are plotted as dashed, dash-dotted, solid lines, respectively. The percentage value above each panel is the variance explained by each mode. 


\subsection{Propagation and Relationship among Associated Fields}

Two leading EOF modes have been commonly used to describe the MJO activities. Lagged correlations based on the principal component (PC) time series can be used to examine the zonal propagation of the MJO. Figure 9 shows lag correlations between two PCs. Positive lag in Fig. 9 means that EOF2 leads EOF1. Since EOF2 and EOF1 correspond to active convection in the Indian Ocean and in the maritime-continents/western-Pacific areas, the lag where correlation reaches maximum values approximates the propagation time from the Indian Ocean to the western Pacific. Fig. 9 indicates that such a propagation time is about 9 days in observations, 6 days in GFS, and 8 days in CFS.

The faster propagation of the convection from the Indian Ocean to the western Pacific in the simulations than that in the observation, as deduced from Fig. 9, does not seem to be in agreement with the wavenumber-frequency power spectra in Fig. 7 which shows that the eastward propagation of the dominant wavenumber 1 components in the simulations is slower (with period around $60-80$ days) than that in the observation (with a period around 40 - 60 days).

Evolution of lag correlation between PC2 and $\chi 200$ is presented in Fig. 10 to help understand this apparent discrepancy. Propagation of negative $\chi 200$ (corresponding to divergent flow and positive convective heating) from the Indian Ocean near $60^{\circ} \mathrm{E}$ at lag $=0$ to $120^{\circ} \mathrm{E}$ takes about 10 days in observations (Fig. 10a), 6 days in GFS (Fig. 10b), and 8 days in CFS (Fig. 10c), consistent with the lag correlation in Fig. 9. Eastward propagation of the negative $\chi 200$ continues throughout the entire globe. In the observation, propagation east of $180^{\circ} \mathrm{E}$ becomes slightly faster because of the weakening of the interaction between condensational heating and large-scale circulation. In the simulations, however, the propagation slows down substantially in the central and eastern Pacific, resulting in an overall slow wavenumber-1 zonal phase speed, in agreement with the results in the wavenumber-frequency spectra in Fig. 7. Power spectra of normalized PC2 in Fig. 11 shows that maximum variance is around 55 days in observation, 60 days in GFS, and 70 days in CFS, consistent with wavenumber-frequency spectra (Fig. 7).

\subsection{Evolution of Associated Fields}

To examine the propagation and the relationship among different fields, we calculated lag correlation between principal components and individual associated fields. The lag

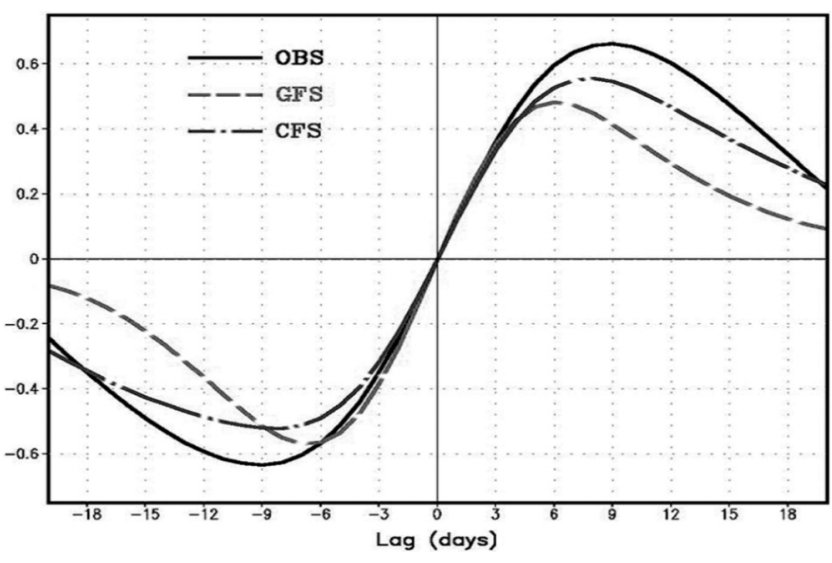

Fig. 9. Lag correlation between two PCs. Positive lag means that EOF2 leads EOF1. (a) OBS

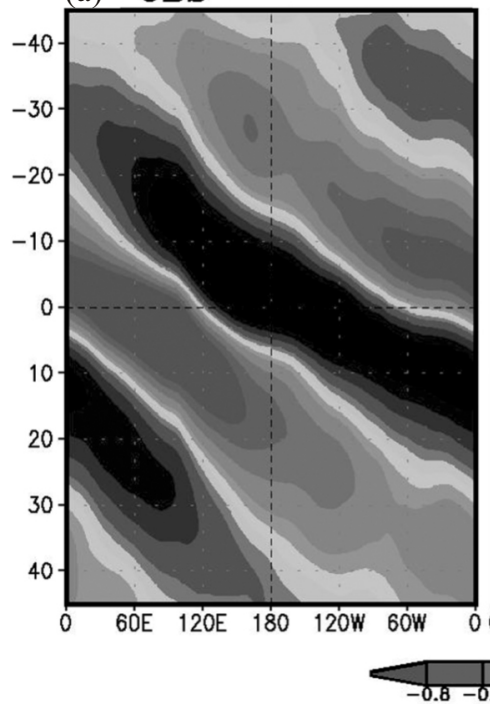

(b) GFS

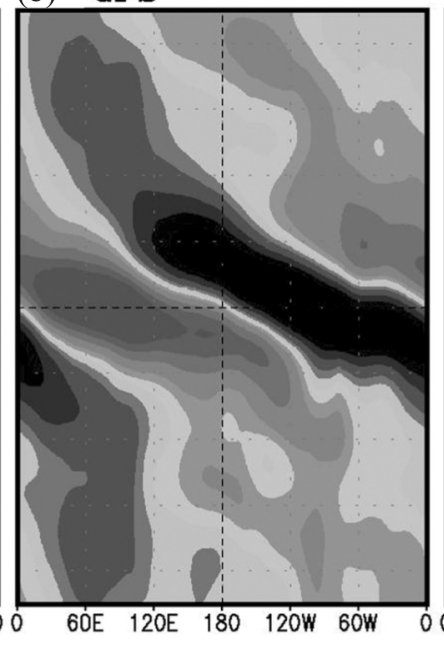

(c) CFS

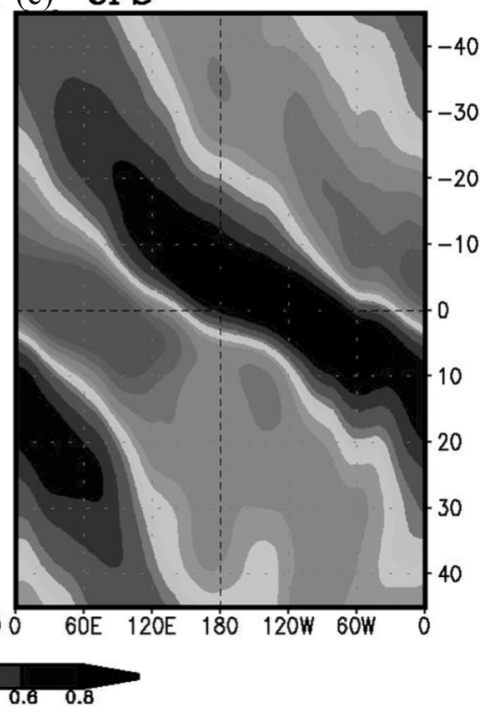

Fig. 10. Lag correlation between $\chi 200$ and PC2. 


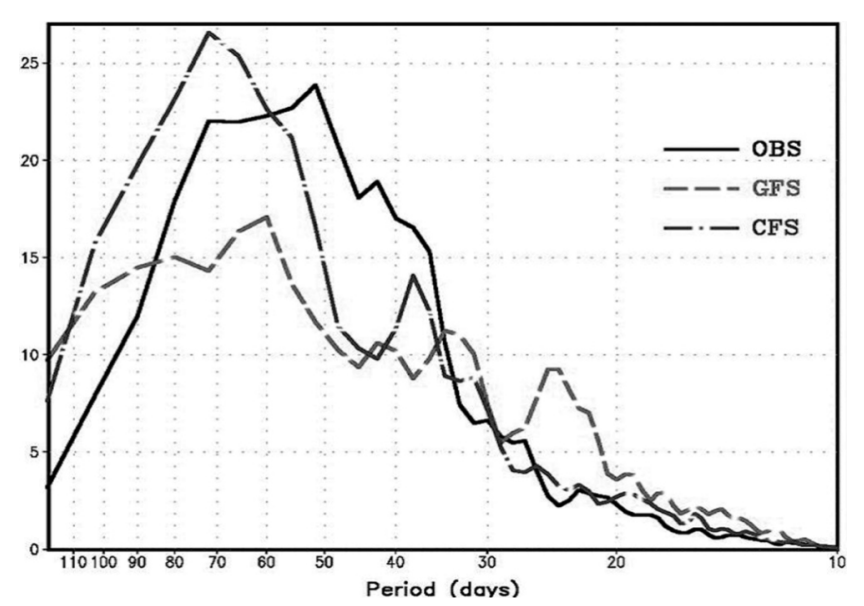

Fig. 11. Power spectra of normalized PC2. correlations between PC2 and individual fields are shown in Fig. 12. Evolutions of precipitation and -OLR are very similar, indicating that these two fields are interchangeable. Their propagation speed is estimated $\sim 4-6 \mathrm{~m} \mathrm{~s}^{-1}$ over the Indian Ocean and western Pacific. Also, a consistent eastward propagation is seen in $\mathrm{u} 850$ and precipitation from the analyses (Fig. 12a). The u850 field shows westerly anomalies to the west of enhanced convection and easterly anomalies to the east of it. Because mean surface zonal winds are weak westerlies over the Indo-Pacific warm pool, enhanced evaporation appears to the west of the convection due to strong vertical mixing and enhanced latent heat flux (LH) to air (where upward is defined as negative flux) and reduced evaporation to the east of the convection (downward latent heat flux to ocean is defined as positive flux). (a) OBS

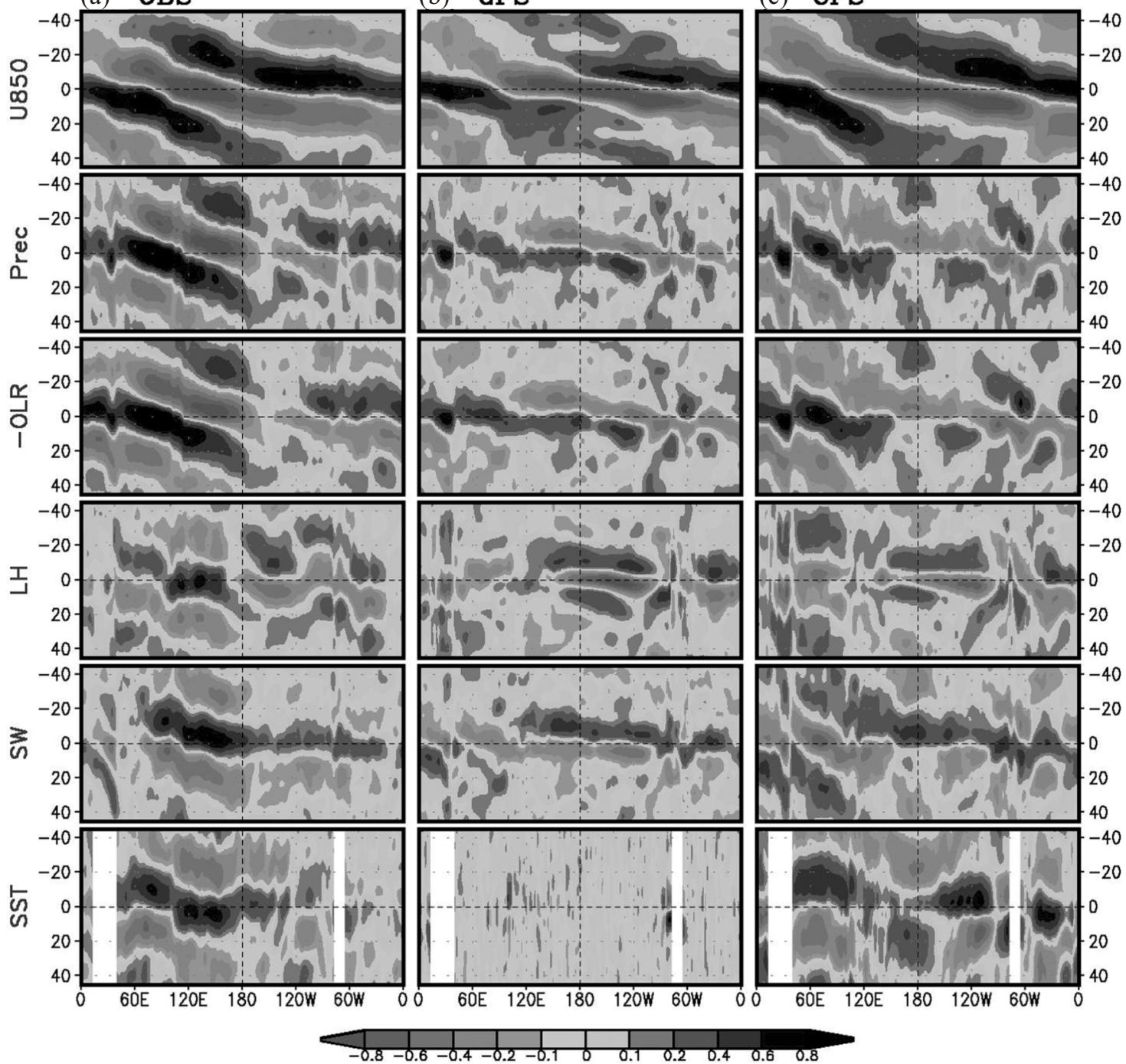

Fig. 12. Lag correlation between PC2 and $850 \mathrm{hPa}$ zonal velocity (u850), precipitation (Prec), OLR, surface net down ward solar radiation (SW), surface downward latent heat flux (LH) and SST. (a) Observations, (b) GFS, and (c) CFS. Values are plotted at -0.8, - - 0.6, - - $0.4,-0.2,-0.1,0,0.1,0.2,0.4$, 0.6 , and 0.8 . 
Also, downward surface shortwave radiation flux (SW) is positive to the east of positive precipitation anomalies or equivalently, in the region of the suppressed convection associated with negative rainfall anomalies. Both LH and SW heat the sea surface and result in an eastward propagation in SST in the Indian Ocean and western Pacific, which helps enhance convection to the east of the existing convection. The surface heating precedes enhanced MJO convection center by a $1 / 4$ cycle ( $\sim 10-12$ days). These surface flux and SST features in the MJO are qualitatively consistent with the conceptual model proposed by Flatau et al. (1997). The improved simulation in CFS implies that the MJO is in part a coupled mode.

Both the GFS and CFS simulated the eastward propagating feature in the observation, but the spatial coherence appears to be improved in CFS compared with those in GFS as seen the regressed fields. For example, enhanced MJO convection in the GFS shows unrealistically fast propagation over the Pacific with a phase speed of $\sim 14 \mathrm{~m} \mathrm{~s}^{-1}$, representing too rigorous convectively coupled Kelvin wave activity, but the propagation in CFS is much improved. This feature is also seen in $\mathrm{u} 850$.

The evolution of LH in both simulations in the western Pacific does not appear to be consistent with that in the analysis, which is likely due the mean errors in surface wind (Fig. 3). As discussed in Inness and Slingo (2003), the mean surface wind is important in determining the LH anomalies. The regressed SW in GFS shows a poor simulation, especially over the Indian Ocean, but the representation of SW in CFS is much improved. SST in CFS also shows a lead-lag relationship seen in the observation (i.e., a quarter cycle difference) and these intraseasonal SSTs are found to organize convection that favors the longer time scales of the $\mathrm{MJO}$, tending to slow the propagation down in a manner close to the observed (Woolnough et al. 2001). Because of the unsatisfactory simulation of the LH anomalies in CFS, the simulated realistic eastward propagation of SST over the Indian Ocean in CFS (Fig. 12c) is primarily due to the contribution of SW anomalies.

The better coherence between the circulation and heating fields, and the consistent evolution of SST in CFS suggests that air-sea coupling is important in the simulation of the MJO. However, the SST errors in CFS also inevitably degrade some aspects in the simulation. In addition to the less realistic surface latent heat flux in CFS, the eastward propagation of convection (precipitation and-OLR in Fig. 12) and the associated upper divergent flow ( $\chi 200$ in Fig. 10) to the east of $130^{\circ} \mathrm{E}$ in $\mathrm{CFS}$ appears to be less continuous compared with the observation. One possible reason for this deficiency is the weak vertical easterly shear in the western Pacific in CFS compared with observation and the GFS simulation (Fig. 4). Zhang and Geller (1994) showed that vertical easterly shear favors eastward propagating waves because it allows the generation of potential energy of the waves. It is thus desirable to employ a numerical model which, while including air-sea coupling, simulates more realistic sea surface temperatures. An additional simulation with the uncoupled GFS forced by SSTs from the CFS simulation will further help understand the role of SST errors in the CFS and this is left to be performed in our future studies.

The propagation of MJO convection from the Indian Ocean to the western Pacific is less continuous in both CFS and GFS (see also Seo et al. 2005). One possible reason of this deficiency is associated with a presentation of convection since the MJO itself is an envelope of convective clusters. Then, a deep convection parameterization will affect the simulation of the MJO. Previous studies show that, along with the need of the fundamental design of convective scheme, the addition of moisture trigger to the cumulus convection scheme tends to produce improved MJO signal (e.g., Tokioka et al. 1988; Wang and Schlesinger 1999). The recent study of Lin et al. (2006) shows that GCMs that employ convective triggers or triggers linked to a moisture convergence simulate the MJO. The active convective activity over the warm pools in climate model induces enhanced lowerlevel circulation, which in turn helps maintain the MJO convection and propagate across the Maritime continent, which is not pronounced in this version of CFS. Therefore, the critical point is the correct feedback between the simulated convection and large-scale circulation and further studies are needed to investigate the representation of the relationship between these.

\section{SUMMARY}

This study examines the fidelity of the MJO simulation by the NCEP uncoupled atmospheric Global Forecast System (GFS) model and the coupled Climate Forecast System (CFS) model based on a 21-year simulation of AMIP-type with GFS and CMIP-type with CFS. Observational data for 1982 - 2002 are used for comparison.

Overall, intraseasonal variability in both the GFS and CFS is stronger than that in the observations, especially for the areas of the maritime continents and tropical centraleastern Pacific where the simulated intraseasonal amplitude is more than $20 \%$ stronger than that observed. The air-sea coupling further enhances the variability in the tropical western Indian Ocean and central-eastern Pacific, and southeastern Pacific stratus deck areas. This enhancement may be associated with local SST warm bias. The amplitude of mean eastward propagating low-wavenumber spectra in GFS is comparable to that in observations but the period of the peak wavenumber-frequency spectra in GFS is around $60-80$ days compared with the observed 40 - 60 days. The CFS simulation retains a similar period range of the peak eastward-propagating wavenumber-frequency spectra as in the GFS simulation, but with the amplitude of the peak spectra being roughly doubled. 
The two leading EOF modes of combined equatorial 850-hPa zonal wind, 200-hPa zonal wind, and OLR are used to represent the MJO in the simulations and observation. EOF1 is characterized by active convection over maritime continents and western Pacific, and the dominant feature of EOF2 is a strong convective peak in the Indian Ocean. Major features of the simulations include:

- Overall patterns of the simulated MJO are similar to that observed;

- Air-sea coupling in CFS improves the coherence between convection and large-scale circulation;

- The too fast propagation of convection from the Indian Ocean to the maritime continents and the western Pacific in GFS is improved (slowed down) in CFS;

- Both GFS and CFS produce large convective heating in the central-eastern Pacific with strong associated circulation anomalies, and the air-sea coupling in CFS further enhances this unrealistic feature. This is one of the model deficiencies that pressingly need improvement because of the strong impacts of intraseasonal variability over eastern Pacific on tropical storm activities and on weather and climate over the Americas;

- The simulated mean slow phase speed of eastward propagating low-wavenumber components shown in the wavenumber-frequency spectra is due to the slow propagation in the central-eastern Pacific in both GFS and CFS;

- Errors in model climatology may have some impact on the simulated MJO. Two possible results are: (i) CFS fails to simulate the westerlies over maritime continents and western Pacific areas, resulting in an unrealistic representation of surface latent heat flux associated with the MJO; and (ii) the vertical easterly wind shear from the Indian Ocean to the western Pacific in CFS is much weaker than that in the observation and in GFS, which may adversely affect the eastward propagation of the simulated MJO.

There are many aspects of the model's performance that still needs to be better understood and improved. Given the irregular nature and variability of the observed $\mathrm{MJO}$, which suggest that the MJO is affected by various factors, and given the difficulty in the model simulations during the past two decades, our understanding of the MJO dynamics and improvement of the model simulation appear to be an incremental process. Clearly, for a model to produce realistic $\mathrm{MJO}$, the following factors should be considered: dynamic interaction between large-scale circulation and convection (e.g., Seo and Kumar 2008), meso-scale processes, cloudradiation interaction, complexity of the processes associated with the maritime continent and hence horizontal/vertical resolutions (e.g., Inness and Slingo 2006), cumulus parameterization (e.g., Zhang and Mu 2005), the vertical structure of a diabatic heating profile and role of stratiform cloud heating (Lin et al. 2004; Boyle et al. 2008), the static stability of the basic state, the vertical shear of basic zonal winds, and air-sea coupling. Lack of realistic representation of any of these processes will likely lead to unsatisfactory simulation of certain aspects of the MJO. On the other hand, to more firmly address the effect of the SST bias on the intraseasonal variability, a comparison between the GFS simulation forced by the observed SST and a new GFS simulation forced by SST generated from the CFS simulation is needed, which is explored in the future.

Acknowledgements The authors would like to thank three anonymous reviewers. Their constructive comments and suggestions greatly improved the original manuscript. This work was funded by the Korea Meteorological Administration Research and Development Program under Grant CATER 2007-4208.

\section{REFERENCES}

Boyle, J., S. Klein, G. Zhang, S. Xie, and X. Wei, 2008: Climate model forecast experiments for TOGA COARE. Mon. Wea. Rev., 136, 808-832, doi: 10.1175/2007MWR2145.1. [Link]

Flatau, M., P. J. Flatau, P. Phoebus, and P. P. Niiler, 1997: The feedback between equatorial convection and local radiative and evaporative process: The implications for intraseasonal oscillations. J. Atmos. Sci., 54, 2373-2386, doi: 10.1175/1520-0469(1997)054<2373:TFBECA >2.0.CO;2. [Link]

Hayashi, Y. and D. G. Golder, 1986: Tropical intraseasonal oscillations appearing in a GFDL general circulation model and FGGE data. Part I: Phase propagation. J. Atmos. Sci., 43, 3058-3067, doi: 10.1175/1520-0469(1986)043<3058: TIOAIA $>2.0 . \mathrm{CO} ; 2$. [Link]

Hendon, H. H., 2000: Impact of air-sea coupling on the Madden-Julian Oscillation in a general circulation model. $J$. Atmos. Sci., 57, 3939-3952, doi: 10.1175/1520-0469 (2001)058<3939:IOASCO>2.0.CO;2. [Link]

Hendon, H. H., 2005: Air-sea interaction. In: Lau, W. K. M. and D. E. Waliser (Eds.), Intraseasonal Variability in the Atmosphere-Ocean Climate System, Springer Praxis Publishing, 223-246.

Hendon, H. H. and J. Glick, 1997: Intraseasonal air-sea interaction in the tropical Indian and Pacific Oceans. J. Climate, 10, 647-661, doi: 10.1175/1520-0442(1997)010 $<0647$ :IASIIT $>2.0$. CO;2. [Link]

Inness, P. M. and J. M. Slingo, 2003: Simulation of the Madden-Julian Oscillation in a coupled general circulation model. Part I: Comparison with observations and an atmosphere-only GCM. J. Climate, 16, 345-364, doi: 10.1175/1520-0442(2003)016<0345:SOTMJO $>2.0 . C O ; 2$. [Link]

Inness, P. M. and J. M. Slingo, 2006: The interaction of the Madden-Julian oscillation with the maritime continent in a GCM. Quart. J. Roy. Meteor. Soc., 132, 1645-1667, doi: 
10.1256/qj.05.102. [Link]

Inness, P. M., J. M. Slingo, E. Guilyardi, and Jeffrey Cole, 2003: Simulation of the Madden-Julian Oscillation in a coupled general circulation model. Part II: The role of the basic state. J. Climate, 16, 365-382, doi: 10.1175/15200442(2003)016<0365:SOTMJO>2.0.CO;2. [Link]

Jones, C., D. E. Waliser, and C. Gautier, 1998: The influence of the Madden-Julian oscillation on ocean surface heat fluxes and sea surface temperature. J. Climate, 11, 1057-1072, doi: 10.1175/1520-0442(1998)011<1057:TIOTMJ $>2.0$. $\mathrm{CO} ; 2$. [Link]

Kanamitsu, M., W. Ebisuzaki, J. Woollen, S. K. Yang, J. J. Hnilo, M. Fiorino, and G. L. Potter, 2002: NCEP-DEO AMIP-II reanalysis (R-2). Bull. Amer. Meteor. Soc., 16311643.

Kemball-Cook, S. and B. Wang, 2001: Equatorial waves and air-sea interaction in the boreal summer intraseasonal oscillation. J. Climate, 14, 2923-2942, doi: 10.1175/15200442(2001)014<2923:EWAASI>2.0.CO;2. [Link]

Kemball-Cook, S., B. Wang, and X. Fu, 2002: Simulation of the intraseasonal oscillation in the ECHAM-4 model: The impact of coupling with an ocean model. J. Atmos. Sci., 59, 1433-1453, doi: 10.1175/1520-0469(2002)059<1433: SOTIOI>2.0.CO;2. [Link]

Krishnamurti, T. N., D. K. Osterhof, and A. V. Mehta, 1988: Air-sea interaction on the time scale of 30 to 50 days. $J$. Atmos. Sci., 45, 1304-1322, doi: 10.1175/1520-0469 (1988)045<1304:AIOTTS>2.0.CO;2. [Link]

Liebmann, B. and C. A. Smith, 1996: Description of a complete (interpolated) outgoing longwave radiation dataset. Bull. Amer. Meteor. Soc., 77, 1275-1277.

Liess, S., L. Bengtsson, and K. Arpe, 2004: The intraseasonal oscillation in ECHAM4 Part I: Coupled to a comprehensive ocean model. Climate Dyn., 22, 653-669, doi: 10.1007/s00382-004-0406-0. [Link]

Lin, J., B. Mapes, M. Zhang, and M. Newman, 2004: Stratiform precipitation, vertical heating profiles, and the MaddenJulian Oscillation. J. Atmos. Sci., 61, 296-309, doi: 10.1175/1520-0469(2004)061<0296:SPVHPA >2.0.CO;2. [Link]

Lin, J. L., K. M. Weickmann, G. N. Kiladis, B. E. Mapes, K. R. Sperber, W. Lin, M. C. Wheeler, S. D. Schubert, A. D. Genio, L. J. Donner, S. Emori, J.-F. Gueremy, F. Hourdin, P. J. Rasch, E. Roeckner, and J. F. Scinocca, 2006: Tropical intraseasonal variability in 14 IPCC AR4 climate models. Part I: Convective signals. J. Climate, 16, 2665-2690, doi: 10.1175/JCLI3735.1. [Link]

Madden, R. A. and P. R. Julian, 1971: Detection of a 40-50 day oscillation in the zonal wind in the tropical Pacific. $J$. Atmos. Sci., 28, 702-708, doi: 10.1175/1520-0469(1971) 028<0702:DOADOI $>2.0 . \mathrm{CO} ; 2$. [Link]

Madden, R. A. and P. R. Julian, 1972: Description of globalscale circulation cells in the tropics with a 40-50 day period. J. Atmos. Sci., 29, 1109-1123, doi: 10.1175/15200469(1972)029<1109:DOGSCC $>2.0$. CO;2. [Link]
Maloney, E. D. and J. T. Kiehl, 2002: MJO-related SST variations over the tropical eastern Pacific during northern hemisphere summer. J. Climate, 15, 675-689, doi: 10.1175/ 1520-0442(2002)015<0675:MRSVOT>2.0.CO;2. [Link]

Pacanowski, R. C. and S. M. Griffies, 1998: MOM 3.0 Manual, NOAA/Geophysical Fluid Dynamics Laboratory, Princeton, USA 08542.

Reynolds, R. W., N. A. Rayner, T. M. Smith, D. C. Stokes, and W. Wang, 2002: An improved in situ and satellite SST analysis for climate. J. Climate, 15, 1609-1625, doi: 10.1175/1520-0442(2002)015<1609:AIISAS >2.0.CO;2. [Link]

Saha, S., S. Nadiga, C. Thiaw, J. Wang, W. Wang, Q. Zhang, H. M. van den Dool, H.-L. Pan, S. Moorthi, D. Behringer, D. Stokes, M. Peña, S. Lord, G. White, W. Ebisuzaki, P. Peng, and P. Xie, 2006: The NCEP climate forecast system. $J$. Climate, 19, 3483-3517, doi: 10.1175/JCLI3812.1. [Link]

Seo, K.-H. and Y. Xue, 2005: MJO-related oceanic Kelvin waves and the ENSO cycle: A study with the NCEP Global Ocean Data Assimilation System. Geophy. Res. Lett., 32, L07712, doi: 10.1029/2005GL022511. [Link]

Seo, K.-H. and A. Kumar, 2008: The onset and life span of the Madden-Julian Oscillation. Theor. Appl. Climatol., 94, 13-24, doi: 10.1007/s00704-007-0340-2. [Link]

Seo, K.-H., J.-K. E. Schemm, C. Jones, and S. Moorthi, 2005: Forecast skill of the tropical intraseasonal oscillation in the NCEP GFS dynamical extended range forecasts. Climate Dyn., 25, 265-284, doi: 10.1007/s00382-005-0035-2. [Link]

Seo, K.-H., J. K. E. Schemm, W. Wang, and A. Kumar, 2007: The boreal summer intraseasonal oscillation simulated in the NCEP Climate Forecast System: The effect of sea surface temperature. Mon. Wea. Rev., 135, 1807-1827, doi: 10.1175/MWR3369.1. [Link]

Sperber, K. R., 2003: Propagation and the vertical structure of the Madden-Julian oscillation. Mon. Wea. Rev., 131, 30183037, doi: 10.1175/1520-0493(2003)131<3018:PATVSO> 2.0.CO;2. [Link]

Sperber, K. R., 2004: Madden-Julian variability in NCAR CAM2.0 and CCSM2.0. Climate Dyn., 13, 769-795.

Tokioka, T., K. Yamazaki, A. Kitoh, and T. Ose, 1988: The equatorial 30-60-day oscillation and the Arakawa-Schubert penetrative cumulus parameterization. J. Meteorol. Soc. Jpn., 66, 883-901.

Waliser, D. E., K. M. Lau, and J.-H. Kim, 1999: The influence of coupled sea surface temperatures on the Madden-Julian Oscillation: A model perturbation experiment. J. Atmos. Sci., 56, 333-358, doi: 10.1175/1520-0469(1999)056 $<0333$ :TIOCSS $>2.0 . C O ; 2$. [Link]

Wang, W. and M. E. Schlesinger, 1999: The dependence on convection parameterization of the tropical intraseasonal oscillation simulated by the UIUC 11-layer atmospheric GCM. J. Climate, 12, 1423-1457, doi: 10.1175/1520-0442 (1999)012<1423:TDOCPO > 2.0.CO;2. [Link]

Wang, W., S. Saha, and H. L. Pan, 2004: Simulation and prediction of the MJO with the NCEP models. Proc. ECMWF/ 
CLIVAR Workshop on Simulation and prediction of Intra-Seasonal Variability with Emphasis on the MJO, Reading, United Kingdom, ECMWF, 237-249.

Wang, W., S. Saha, H. L. Pan, S. Nadiga, and G. White, 2005: Simulation of ENSO in the new NCEP Coupled Forecast System Model (CFS03). Mon. Wea. Rev., 133, 1574-1593, doi: 10.1175/MWR2936.1. [Link]

Wheeler, M. C. and H. H. Hendon, 2004: An all-season realtime multivariate MJO index: Development of an index for monitoring and prediction. Mon. Wea. Rev., 132, 1917-1932, doi: 10.1175/1520-0493(2004)132<1917: AARMMI $>2.0 . \mathrm{CO} ; 2$. [Link]

Woolnough, S. J., J. M. Slingo, and B. J. Hoskins, 2001: The organization of tropical convection by intraseasonal sea surface temperature anomalies. Quart. J. Roy. Meteor. Soc., 127, 887-907, doi: 10.1002/qj.49712757310. [Link]

Woolnough, S. J., F. Vitart, and M. A. Balmaseda, 2007: The role of the ocean in the Madden-Julian Oscillation: Sensitivity of an MJO forecast to ocean coupling. Quart. J. Roy. Meteor. Soc., 133, 117-128.

Xie, P. and P. A. Arkin, 1997: Global precipitation: A 17-year monthly analysis based on gauge observations, satellite estimates and numerical model outputs. Bull. Amer. Meteor. Soc., 78, 2539-2558, doi: 10.1175/1520-0477(1997)078 $<2539$ :GPAYMA>2.0.CO;2. [Link]

Zhang, C., 1996: Atmospheric intraseasonal variability at the surface in the tropical western Pacific Ocean. J. Atmos. Sci., 53, 739-758, doi: 10.1175/1520-0469(1996)053 $<0739$ :AIVATS $>2.0 . \mathrm{CO} ; 2$. [Link]

Zhang, C., 1997: Intraseasonal variability of the upper-ocean thermal structure observed at $0^{\circ}$ and $165^{\circ} \mathrm{E}$. J. Climate, $\mathbf{1 0}$, 3077-3092, doi: 10.1175/1520-0442(1997)010<3077: IVOTUO $>2.0 . \mathrm{CO} ; 2$. [Link]

Zhang, G. J. and M. Mu, 2005: Simulation of the MaddenJulian Oscillation in the NCAR CCM3 using a revised Zhang-McFarlane convection parameterization scheme. J. Climate, 18, 4046-4064, doi: 10.1175/JCLI3508.1. [Link]

Zhang, M. H. and M. A. Geller, 1994: Selective excitation of tropical atmospheric waves in Wave-CISK: The effect of vertical wind shear. J. Atmos. Sci., 51, 353-368, doi: 10.1175/1520-0469(1994)051<0353:SEOTAW>2.0.CO;2. [Link] 